\title{
At the Cross Roads: Families in Distress
}

\author{
Rajni Dhingra* and Vaishali Arora \\ Post Graduate Department of Home Science (Human Development), University of Jammu, \\ Jammu 180 004, Jammu \& Kashmir, India
}

KEYWORDS Internal Displacement. Migration. Conflict. Change. Kashmiri Pandit Families

\begin{abstract}
The present paper is based on the review of studies conducted in Jammu and Kashmir (India) on the effect of militancy and consequent migration on the displaced Kashmiri Pandit families. The available data indicates that displacement has led to marked changes in their life style, family structure and relationships. Many of these families are dependent on government relief for their survival. Due to lack of privacy in one room tenement, the fertility rate is facing downward trend. They are suffering through financial setback. These displaced families are frustrated because of their inability to cope up with the demands of each family member and as a result there is an increase in the incidence of family disruption. The worst hit section of community is students. They do not have adequate facilities available to them for education and recreation. Kashmiri Pandit children visualize themselves as segregated part of this society, having feeling of uprootedness and alienation deep in their heart. This future generation of Kashmiri Pandits is moving through a perilous path of cultural homogenisation, thereby loosing their identity. On the basis of review of these changes, intervention strategies and suggestions are provided for the researchers and policy makers.
\end{abstract}

\section{INTRODUCTION}

Kashmir, which is an important and integral part of Indian land, known for its natural beauty, has today become a land of atrocities. The fourteen-Year- old armed conflict in Jammu State has disturbed various dimensions of human life: personal, social and political among others. Before the outbreak of militancy, the situation in valley was peaceful. Prior to migration, families were living cohesively and there was a strong bond of relations within and outside the family. The economic condition of the families was stable and literacy rate among them was very high. The share of Kashmiri Pandits in the higher posts of State Government jobs and Central Services was considerably higher. Due to the onset of militancy in the state in 1989, a large number of Kashmiri Pandits have migrated from valley and moved to various places in India. A large majority of settlements have been in Jammu (Jammu and Kashmir), the winter capital of the state. The group under focus (Kashmiri Pandits) has been an integral part of the various communities in Kashmir.

The total population of Jammu \& Kashmir in North of India is 1,00,69,917 (Digest of

*Corresponding Author: Prof. Dr. Rajni Dhingra, Head, Post Graduate Department of Home Science (Human Development), University of Jammu, Jammu 180004 , Jammu \& Kashmir, India

Telephone: 0191- 2457137; Fax: 0191- 2457137

E-mail: rajni_dhingra@rediffmail.com
Statistics, 2001) and out of this the Hindu population in the State is 19,30,448. Kashmiri Pandits are concentrated in Kashmir valley. They constitute nearly $8 \%$ of Kashmir's population. Kashmiri pandits form a distinct class of their own. They are all Brahmins, but do not follow the rules and restrictions normally observed by other Brahmins in India. Mostly the Kashmiri pandits are nonvegetarians. Vegetarians among Kashmiri pandits eat vegetables, lentils, rice, flour-bread, yoghurt, etc. Non-vegetarians eat mutton, fish, fowls with rice and flour bread. Hindus keep their heads covered with a cap, turban, towel, or broad scarf while they are at prayers or enter some shrine or temple for worship. They are divided into two groups: Malmasi and Banmasi. The former follow the lunar calendar while latter who are in majority follow the solar calendar. Karkuns and Bhashyabhats are the two sub castes. Basically Kashmiri Pandits constitute a small highly advanced community, with more than $90 \%$ of them being highly literate. Their chief occupation is Government service. Only a few are in other jobs or trades. Practically none of them pursues farming as a main occupation.

In the year 1990 migration took place throughout valley. Murder, loot and inhuman practices like branding with hot iron, lynching, burning alive etc. by terrorists, compelled Kashmiri Pandit families to move out of their motherland, within short span of one week to fortnight (Zutshi, 2003). Migration was the only way out for them to save their skins, which changed their life style. 


\section{INFLUENCES ON FAMILIES}

The present review of available studies has been undertaken so as to determine the consequences of migration on life style, rolerelationships among family members, and changes in family dynamics of Kashmiri Pandits. Placement in a particular ecological setting drastically changes the life patterns of the group. For Kashmiri Pandits, forced migration has led them to geographical areas grossly incomparable to their original habitation in terms of weather conditions and assets available. From lush green cold environment, they have landed into hot and dry areas, which they find totally uncomfortable. From luxurious open houses, several of them have been forced to reside in crampled one-room tenements, thus altering the very essence of their whole life. According to a study conducted by

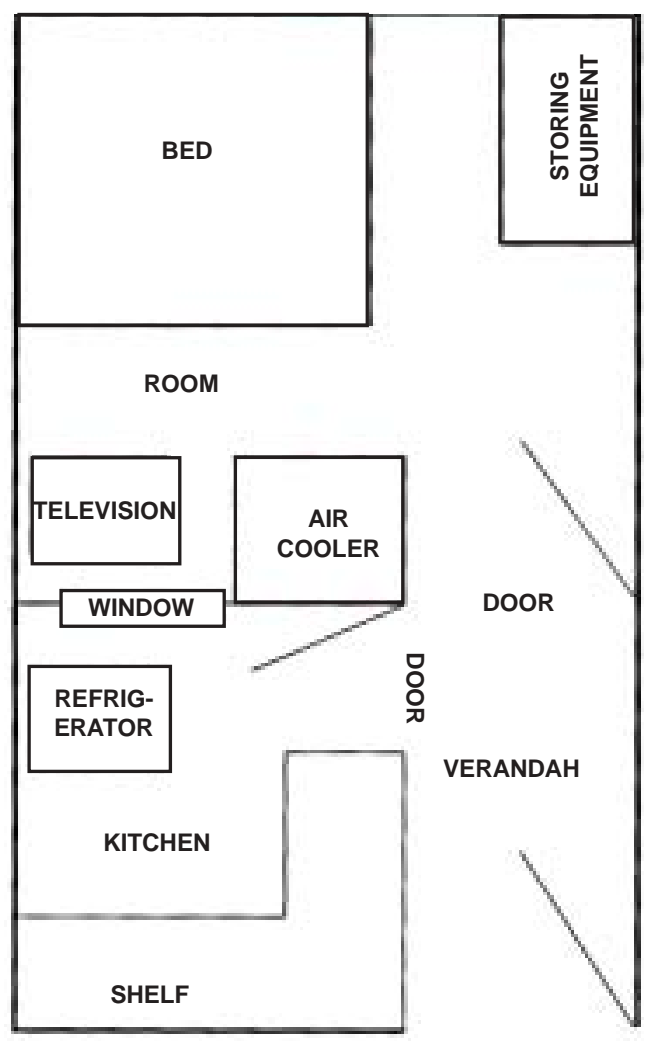

ENTRANCE

Fig. 1. Average Dwelling Dimesion 9' x 12' (Figure not to scale)

Floor plan of a Tenement of muthi camp Phase-1
Dhingra et al. (2003) at Muthi, one of the migrant camps in Jammu, it was found that the whole camp is divided into two phases, each phase having 5 blocks (A, B, C, D, E). In each block, approximately 100 families are accommodated. Both the phases have different exterior and similar interior plans. In phase I, each family is residing in an individually constructed one-room quarter having a verandah (open space on the outer portion of the house). The inhabitants are using more than half of the portion of verandah as Kitchen. Each block consists of 12 toilets and 12 bathrooms (6 each for male and females). These are to be shared by the families residing in that particular block only. In phase II, four different families live under one roof having four rooms, one room for each family. All these rooms have their individual entrance and verandahas. These four families share one toilet and bathroom, which are locked after every use. The basic items which the residents posses in these tenements are double beds, television, refrigerator, air cooler, almirah and rack (see Fig. 1). All the families have floorsitting arrangement. No financial assistance is provided to these displaced families for purchase of such commodities.

There was a time when Kashmir migrants were enjoying their life in their own houses in the beautiful valley. But at present, life has become merely a compromise. Raina (1994) revealed that these migrants have been forced to live in camps under economic, social and emotional trauma. Traders could not be compensated; unemployed not provided with jobs, individuals old as well as young are trying to cope up with changed environment. They have been forced to live the life of exile in their own country, outside their homeland in temporary hutments and in subhuman conditions in various refugee camps in Jammu, Delhi and other parts of country. According to the census of Kashmir displaced families conducted by Kashmir Samiti (Delhi) in 1999, 3,60,385 persons both in Jammu and Delhi have been displaced from Kashmir valley due to armed conflict (Zutshi, 2003). The other displaced families are from Jammu division, especially from Poonch, Doda, Kishtwar, Baderwah \& Rajouri, (the data for these regions is not available). These displaced families are encountered with number of challenges and changes but still they have tried and managed to restart their lives.

The displaced Kashmiri Pandits are residing in several rehabilitation camps and newly built 
up residential colonies in the outskirts of Jammu. Government is providing relief to those displaced families who have registered themselves as migrants and have no other source of income after migration. Those who were government employees prior to migration were adjusted in their respective departments, in Jammu, Delhi and other parts of country. Table 1 shows the relief measures provided by the central Government (distributed by state government) to migrant Kashmiri Pandits families. The total amount of relief given is for four family members only. If the number of family members is more than four, even then the amount is restricted to Rs. 2400 . But in case the number of members is less than four i.e. 3 or 2 the amount is curtailed accordingly, like Rs. 1,200 for family of two members. In terms of ration provided to families, if a family is having a newly born baby then it is provided with an extra quantity of sugar (250 gms per month) for next 4 years.

On the economic front displaced families have been hit hard. According to survey finding of Ali et al. (2001), when the intensity of militancy increased, they were forced to leave their movable and immovable property. It was so instant that they did not get a chance to dispose off their

Table 1: Relief measures provided to Kashmiri Pandits by Government

\begin{tabular}{|c|c|c|}
\hline S. No. & Relief measures & Amount/Quantity \\
\hline 1. & Financial Assistance & Rs. 2,400 per family \\
\hline \multirow[t]{4}{*}{2.} & Food (Ration) & \\
\hline & Rice & $9 \mathrm{Kg}$ per month \\
\hline & Wheat & $2 \mathrm{Kg}$ per month \\
\hline & Sugar & $1 \mathrm{~kg}$ per month \\
\hline 3. & Accommodation & One big room + verandah \\
\hline
\end{tabular}

property. They perceived that migration was temporary and left, with whatever little they could carry. Now, their financial condition is grim. The real problem is for those people whose primary jobs were related to agriculture. It was also reported that respondents have lost everything and they had to start from the zero level. About $90 \%$ of respondents showed their displeasure regarding the income structure. As a result they are suffering from various shortcomings in their life.

It is invariably true that ecological and economic aspects of life ultimately affect the socio-cultural patterns and the ideology of beliefs, values and attitudes of a group (Minturn and Lambert, 1964). With the above documented changes in the physical aspects of life of Kashmiri Pandit Families, there are bound to be changes in role-relationships in their families. It was noted that the immediate fall out of migration was very high increase in number of nuclear families. The traditional joint families were forced to split up due to lack of adequate accommodation. Even the elders in the family accepted such division due to their helplessness. With the collapse of traditional joint family structure, the support of an integrated family is missing. This is bound to lead to its natural consequences like inadequate child care support systems for working women, growing feeling of individualism and increased feeling of loneliness (Parasuraman, 1986).

The displaced families lack privacy. The condition was so bad initially that several families were forced to live in tents/single room portioned by sheets of worn out linen cloth. As Dewan (1994) reported that in one of the migrant camp (Mishriwala) in Jammu, the families had to sit, eat and sleep in single room only. Parents, students and teachers, all of them complained about the disarray of education system which created frustration among the students. They don't have separate place to study or play. Also, the findings of the survey conducted by Rajput et al. (2001) revealed that people do not have privacy in their family because they have been provided only one room in which they have to manage everything which seems not only difficult but also impossible. People do not enjoy marital privacy in the camps. As a result, the birth rate has declined in past decade. According to a report published by Panun Kashmir (1995) based on a sample survey conducted in migrant camp during 1990-1995, it was found that among 300 families, having 1,265 inmates, 16 births and 49 deaths, had taken place. Another report in Times of India (5 July 1995) shows that among 350 families, having 1,200 inmates, only 5 births took place while 200 people died. So, the data shows decline of birth rate with a higher death rate. As a result of this imbalance, the Kashmiri Hindu population is shrinking. Other reasons responsible for the fast fall in population are premature menopause in women, hypofunction of reproductive system, delayed reproduction or infertility, malnutrition, sunstroke and snakebite. Chowdhary (1997) also reported that Kashmiri Pandits had aged physically and mentally by $10-15$ years. They have been suffering from premature aging, premature decline in mental faculties and premature deaths. 
The roles and relationships of the family members have been challenged in the wake of altered living conditions. The male members of the Kashmiri Pandit community are no longer satisfied with the kind of role they are playing these days. They feel that they are no longer capable of taking the responsibility of running their homes, as they do not have good jobs that they had earlier. Government is providing them relief and they are dependent on it. This has produced a feeling of dependence and self-pity. In a survey conducted in refugee camps, one of the respondents stated that United Nations High Commission for Refugees (UNHCR) now provided housing for his family, food for kids and clothing for his wife. "What use am I any more"? was the question he asked (John, 2003). This kind of challenge to their traditional role as providers for their families tends to lead to anger, frustration, uncertainty and helplessness among male members and sometimes this translates into violence against women in the family. Women are facing double stress. Firstly, it is the stress of migration that she has to bear and secondly being the weaker sex, she also faces stress in family due to internal tension.

Studies have also reported an increased rate of disruption in the affected population. Since the displaced families lack accommodation and other assets, they originally possessed and have to bear drastic changes in climatic conditions, it is required that their individual needs, habits and behaviour patterns of sleep and work are modified, changed and adjusted to the needs and conveniences of other members of family. Faced with the need to make gross adjustments in a very short span of time, it has resulted in brooding over the past events, property left, loss suffered and other related issues. This leads to further feeling of anxiety, depression and aggravation of symptoms, which is translated to violence and frustration among family members. More and more conflicting situations are arising day by day among displaced families. This is visible in the form of increase in divorce cases among Kashmiri Pandit couples. The matrimonial court records also show the unprecedented trend in marriage disputes among Kashmiri Pandit community. Out of over 900 cases registered by court, 300 have been initiated by Kashmiri Pandit in year 2001. Maximum number of couples that approached the court for divorce are in the age group of 24-40 years. It is the children in the family who have to suffer. Children become the scapegoat due to the dispute between parents. They are dragged to court for no fault of theirs. Their future has been put at stake (Bhat, 2002).

Another important area affected by conflicting situation in the state of Jammu and Kashmir is the cultural life of migrants. Migra-tion has distorted their cultural identification. They describe their identity by language, clothing, and food habits and marriage patterns. But now they feel that there are some forces, which compel them to leave characteristics of their culture. For Kashmiri Pandits, the word Citizen has been replaced by Migrants. The young generation is now most susceptible to the dangerous aspects of homogenisation with their peers. Their food pattern has also changed. There are changes in the pattern of solemnization of marriage. The number of choice and intercaste marriages is increasing. There are changes in social relationships and family values. The community has lost hopes of organization of cohesive social and political entity, which is vital for its survival.

\section{INFLUENCES ON CHILDREN}

Children constitute about $38 \%$ of Jammu and Kashmir State population. Out of these, 5 to $6 \%$ children are either orphans, destitute or neglected ones, who do not get basic needs fulfilled in the present turmoil. While looking at the child group in Jammu and Kashmir, adequate emphasis needs to be given to the psychological, physical and social aspects of development and their interactive effects. These children are under the influence of terror; they suffer from physical and psychological disturbances. As reported by a prominent Psychiatrist from Kashmir, (c.f. Madhosh, 2001) the magnitude of psychiatric disorders during 1990-1994 has been the highest ever since 1989. It rose from 1762 cases in 1990 to 17,584 cases in 1994 . More than 800 Pandit children during 1990-1997 had developed acute psychological trouble without any anatomical reason. These children have been witnessing cruelty in the hands of militants. They have seen heaps of dead bodies and pools of blood everywhere, in and outside home. They have horrifying stories to narrate of their plight and sufferings (Razdan, Personal communication, 2003).

Another sector affected by militancy is education. The number of dropouts has increased. The student community also feels 
disheartened on account of delay or postponement of examination. The educational facilities provided in the camps are inadequate because of lack of proper infrastructure and staff. There are no libraries, laboratories, no recreational facilities, and no facilities to display and promote talents. So, the number of students on roll is decreasing constantly day-by-day.

Survey conducted by Sagar (2001) revealed that children who have lost their parents are rendered homeless and there is nobody to guide them towards the right direction. Many of them are facing cruelty at the hands of surviving relatives in the form of negligence and rejection, which have shattered the feeling of security in them. Very few institutions have come up to take the responsibility of these parentally deprived children. In case of children, those who were in the middle of their childhood have very clear impression of the process of displacement. They have gone through trauma of both militancy as well as their uprootedness from the native land. They claim that the best period of their life was devoted to the struggles attached with living in the camps and restoring the meaning and sense of whatever was left in the life. These children feel very much embittered, because instead of joys of childhood fantasies and playfulness, these children had to struggle adjusting with the new environment of camps devoid of even basic facilities. A study conducted by Dhingra and Watal (1995) on Kashmiri Pandit migrant children in the age group 8 to 10 years revealed that the negative feelings and stress associated with migration were perceived to be present not only at the conscious level, as witnessed in the present behaviour patterns but had deep set roots. By administration of a projective test (Children's Aptitude Test) on children, it was found that stress seems to have affected their unconscious personality, thereby making the impact much more lasting, fixed and having long-term consequences.

\section{CONCLUSION}

The family has been recognized as an important unit of society because of the role it plays in generation of human capital resource and the power that is rested in it to influence individual, household and community behaviour (Sriram, 1993). Any change in the ecological and sociological setting, especially of the kind witnessed due to forced migration, is bound to have multiplicity of effects on this important and basic institution. A brief overview of research on the impact of militancy on Kashmiri Pandit displaced families has revealed that their family as a unit is facing tremendous struggle and threat for survival. Their living conditions have altered dramatically and economic powers reduced drastically. Several studies conducted on families in similar situation, such as the one conducted by Marshal (1995) at whale head, Hong Kong's biggest refugee camp and Gupta (1997) in war affected Kabul (Afghanistan) have also revealed similar plight of the affected families. At the socio-cultural and emotional level, it has been noted that there is increase in family disruption, accompanied by high level of stress and psychological trauma among the family members. As suggested by Dabla (1999) the families are undergoing the process of transformation and family as an institution is battling for survival.

Since family consists of close network of individuals, the effect of stress in the family percolates to various members. The effect is more serious on the younger individuals. It has been pointed out by many studies quoted above that Kashmiri Pandit Children are facing severe emotional and behavioural problems in the form of depression, anxiety, aggression, and sleeplessness. Singh (2000) studied children affected by terrorism in the Indian state of Punjab and found that a large number of children were rendered orphans and faced the trauma over the killing of their parents. These victims passed through moments of anxiety and mental torture, stress and strain. Several studies conducted on children in various settings outside India have also documented the similar effects. Drummond (1993) conducted a survey on Bosnian refugee children and found that they suffered from guilt feelings because they survived while their loved ones perished. Many of them had become withdrawn and even violent. These children felt that their lives were meaningless. Similarly, Masser (1992) revealed that American Refugee Children reported pre-migration, immigration related and post-migration stressors. Results indicated interruption of growth process among children. Migrated children in Jammu and Kashmir have wasted their beautiful childhood years in their struggle to settle down in new environment and in search for their identity. 


\section{IMPLICATIONS AND INTERVENTION STRATEGIES}

The above discussion clearly reveals an urgent need for a timely and holistic intervention plan which could effectively counter the negative impact thus suffered. The first and the foremost step in this area is to find a permanent solution to the Kashmir imbroglio. In the mean time, there is need to provide psychiatric assistance to the affected families, both in rural and urban areas of the state so as to help them come out of their psychological problems. For this purpose mobile psychiatric clinics could be started. Family and child help lines as well as counselling programmes including family therapy are needed. Further research needs to be carried out with the affected population so as to build a strong database for intervention planning. It has been found by many studies that measures such as yoga, meditation etc. that aim towards selfrealization help improve the coping ability of individuals in crises situation. Such relaxation therapies should be systematically introduced in various institutions dealing with children and adults. Multi-disciplinary approach i.e. involvement of professionals from different fields like, education, medical, social work etc. should be used for rehabilitation of displaced families. Counselling programmes should be organized about how to deal with victimized families and how parents and teachers should deal with the children immediately after disaster and later on. Peace education curriculum should be planned and provided to all the educational institutions, which should deal with key concepts of disaster, typical reaction to it according to different age groups and helpful hints (Madosh, 2001).

\section{REFERENCES}

Ali, F., Sudan, A. and Vivek, P: Survey Report of SES: Some Reflections. University of Jammu, Jammu, India (2001).

Bhat, A: Orphans of an Unfortunate Conflict. www. kashmirhrnet/mainfilephp/articles/46/ (25-02-2002).

Chowdhary, K.L.: Hazards of Forced Migration. Koshur Samachar, 41(5): 34-35 (1997).

Dabla, B. A.: Kashmir Family: Besieged Stressfully. Sensor: Sunday Supplement of Greater Kashmir (10-01-1999).

Dewan, R.: Women Testimonies from Kashmir. Economic and Political Weekly, 30(4): 7-9 (1994).

Drummond, T.: Children Especially in Difficult Circumstances. My Name is Today, 1(1): 112-113 (1993).

Dhingra, R., Arora, V. and Sharma, Y: Correlates of Adjustment Among Kashmir Pandit Migrant Adolescent Girls (1518 Years). University of Jammu, Jammu, India (2003).

Dhingra, R. and Watal, R.: Impact of Migration on Children Belonging to Kashmiri Pandit Community. University of Jammu, Jammu, India (1995).

Digest of Statiststics. Government of Jammu and Kashmir. Directorate of Economics and statistics Planning and Development Department, Jammu (2001).

Gupta, L: Psychosocial Assessment of Children Exposed to War-Related Violence in Kabul- Afghanistan. UNICEF Report (1997)

John, N.: Suppressed Womenhood: A Cry for Rights. Gayan Publications, New Delhi (2003).

Madhosh, A.G.: Children Under Armed Conflict in J\&K. Paper Presented in Seminar on Children in Difficult Circumstances, at P.G. Department of Home Science, University of Јатти, Јатти, India (2001).

Marshal, R.: Final Act: Closing Down the CPA. Refugee, 1: 910 (1995).

Masser, D.: Psychological Functioning of Central American Refugee. Child Welfare, 21(6): 442-448 (1992).

Minturn, L. and Lambert, W.W.: Mothers of Six Cultures. Wiley, New York (1964).

Parasuraman, S.: Migration and its Effect on the Family. Indian Journal of Social Work, 47 (1): 1-14 (1986).

Panun Kashmir Movement Memorandum. Report on Human Rights Violation (1995).

Raina, D. N.: Kashmir Distortion and Reality. Reliance Publishing House, New Delhi (1994).

Rajput, S., Sharma, S., Sambyal, O. and Kanfar, P: Survey Report on Kashmir Migrants. University of Jammu, Jammu, India (2001).

Sagar, D.: Militancy and Children in Jammu and Kashmir. wwwpunjabilok com/2001 (2001).

Singh.: Violence and Socialization of Traumatized Children in Punjab. www punjabilok.Com /2000 (2000).

Sriram, R.: Family Studies in India: Appraisal and New Directions, pp. 122, In: Human Development and Family Studies in India. T. S. Saraswathi and B. Kaur (Eds). Sage Publications, New Delhi (1993).

Zutshi, B.: Status of Widow of Kashmir: The Displaced Population, In: Living Death: Trauma of Widowhood in India. V.M. Giri. (Eds.) Gayn Publications, New Delhi (2003). 